\title{
LA INFORMACIÓN GRAMATICAL EN LOS DICCIONARIOS MONOLINGÜES DE APRENDIZAJE: REFLEXIONES A PARTIR DEL VERBO
}

\author{
ISAREt, Santamaría Pérez \\ Universidad de Alicante \\ mi.santamaria@ua.es
}

\begin{abstract}
Resumen
This paper is about the lexicography treatment of verbs in learners' dictionaries. We study if this kind of dictionaries includes enough grammatical information of this items to achieve an active use of thems.
\end{abstract}

I. LA LEXICOGRAFÍA DIDÁCTICA EN LOS ÚLTIMOS AÑOS: DICCIONARIOS MONOLINGÜES DE APRENDIZAJF

Tal y como viene reconociendo la teoría lexicográfica, los diccionarios deben elaborarse atcndicndo a las necesidades de sus usuarios y en los últimos años el destinatario se ha convertido en uno de los principales parámetros de diferenciación de las obras lexicográficas.

Es cicrto que en otras lenguas, como el inglés, que cuentan con una larga tradición en la enseñanza de esta lengua como lengua extranjera, se toman cn consideración las necesidades de los usuarios, especialmente cuando se enfrentan al aprendizaje de una segunda lengua, y ello ha traído consigo la eclosión de la lexicografía pedagógica, didáctica o de aprendizaje!, pero en el ámbito de la lexicografía española esta modalidad lexicográfica no se ha visto atendida hasta hace relativamente poco ticmpo, ya que no se habían elaborado diccionarios que tuvieran en cuenta el destinatario y sus necesidades específicas. Es en los años noventa, con la instauración de la LOGSE ${ }^{2}$, cuando este panorama empieza a cambiar y aparecen diccionarios elaborados según las necesidades del tipo de destinatario y su función didáctica. No obstante, a pesar de los éxitos alcanzados en los últimos tiempos, la lexicografía de carácter didáctico presenta todavía importantes lagunas como por ejemplo «establecer la

\footnotetext{
1 Se trata de los llamados learners' dictionary, diccionarios monolingües ingleses de aprendizaje, los cuales han reflejado en el diccionario las investigaciones lingüisticas y metalexicográficas y se elaboran en función del tipo de destinatario (Azorín \& Martínez Linares, 2001: 362).

2 A partir del establecimiento de esta ley, se recoge una nueva concepción del estudio de la lcngua, basada en criterios contextuales y discursivos, prencupada por cuestiones sociolingüísticas y enfocada al desarrollo y potenciación de las capacidades comunicativas orales y escritas del alumno. Desde este punto de vista la gramática y el diccionario sc convierten en dos instrumentos fundamentales para el desarrollo de las capacidades y lus destrezas lingüisticas de los alumnos.
} 
tipología de los usuarios, determinar cuáles son sus necesidades y cuáles las destrezas que deben desarrollar» (Hernández, 1998: 50).

Con cl avance de la lingüística aplicada en el ámbito de la enseñanza de lenguas se diferencian dos procesos diferentes para conseguir el conocimiento y dominio de una lengua. Por un lado, sc distingue la adquisición, proceso espontáneo e inconsciente de internalización de un sistema lingüístico como consecuencia del uso natural del lenguaje con fines comunicativos y sin atención expresa a la forma y, por otro, el aprendizaje, proceso consciente que se produce a través de la instrucción formal en el aula e implica un conocimiento explícito de la lengua como sistcma (Santos Bargalló, 2000: 19-20). De manera que la adquisición se relaciona con la lengua materna y el aprendizaje con la lengua extranjera ${ }^{3}$. Si establecemos procesos distintos para aprender y lograr el conocimiento de una lengua, tendremos que distinguir métodos y estrategias distintas en el aprendizaje-enseñanza de una lengua materna o una lengua extranjera. De la misma mancra, procesos de aprendizaje distintos requerirán instrumentos y materiales diferentes.

Partiendo de que hoy nadie pone en duda que el diccionario es un instrumcnto fundamental en el proceso de enseñanza-aprendizaje de una lengua y que hay diccionarios que están especialmente diseñados y elaborados para ayudar en ese proceso de aprendizaje de una lengua, habrá que elaborar diccionarios diferentes para cada usuario con necesidades distintas en ese largo proceso de conocimiento de la lengua.

Siguiendo a H. Hernández (1993: 193), podemos diferenciar varios tipos de obras lexicográficas depcndiendo de quién sea el destinatario, ya que no es lo mismo un usuario con conocimiento y dominio del idioma que un usuario que se encucntra en fase de aprendizaje, bien de su lengua materna, bien de una lengua extranjera. Frente a los primeros que precisan de repertorios generales, los segundos son destinatarios que presentan lagunas y carencias de las estructuras lingüísticas y las reglas que regulan su actualización en el discurso; esto es, los estudiantes no nativos presentan deficiencias en el conocimiento productivo y reccptivo de la lengua. Pero dentro de este conjunto de usuarios en fase de aprendizaje, tampoco hallamos cl mismo nivel de competencia lingǘrstico-comunicativa: no presenta el mismo grado de incompetencia un escolar que perfecciona cl uso de su lengua materna que un extranjero que aprende una lengua distinta a la suya $y$, por tanto, tampoco podrá tener las mismas necesidades de aprendizaje ni podrá utilizar el mismo tipo do instrumentos auxiliares para alcanzar las destrezas comunicativas receptivas o productivas, sean manuales, gramáticas o diccionarios.

Centrándonos ya en las obras de carácter lexicográfico, aunque todos los diccionarios son obras didácticas, no todos persiguen los mismos objetivos ni están pensados para el mismo público. Así pues, la lexicografía didáctica destinada a aquellos que se encuentran cn proceso de aprendizaje de una lengua debe diferenciar:

\footnotetext{
3 Igual que se diferencia el tipo de proceso de conocimiento de una lengua a partir del contexto en que se lleva a cabo la internalización del nuevo sistema linguíístico y cultural, se puede establecer la siguiente dicotomía dependiendo del papel que lenga la lengua meta en el ámbito geográfico en que se desarrolla el proccso: lengua segunda, aquella que cumple una función social e institucional en la comunidad lingüística en que se aprende y lengua extronjera, la que se aprende cn un contexto en el que carece de función social e institucional. Actualmente, en la bibliografía existente sobre el tema se suelen emplear ambos términos como sinónimos. En este trabajo, utilizaremos la denominación de lengua exíranjera en sentido estricto.
} 
1. Aquellos diccionarios que tienen como objetivo servir de apoyo a la enseñanza de la lengua materna: diccionarios escolares (DE)

2. Aquellos que se destinan al aprendizaje de lenguas extranjeras: diccionarios monolingües de aprendizaje (DMA).

\begin{tabular}{|c|c|}
\hline \multicolumn{2}{|c|}{ DICCIONARIO DIDÁCTICO } \\
(objetivo: enseñanza/aprendizaje de lenguas) \\
\hline $\begin{array}{c}\text { DICCIONARIO ESCOLAR } \\
\text { (enseñanza/aprendizaje de la lengua materna) }\end{array}$ & $\begin{array}{c}\text { DICCIONARIO DE APRENDIZAJE } \\
\text { (enseñanza/aprendizaje de la lengua extranjera) }\end{array}$ \\
\hline
\end{tabular}

Cuadro 1. Tipologia de diccionarios didácticos (Azorín, 2000)

Asimismo, en el artículo mencionado (Hcrnández, 1993; 193) se diferencian dos tipos de diccionarios para los usuarios no nativos: por un lado, el diccionario bilingïe y por otro, el diccionario monolingüe de aprendizaje. No debemos olvidar que el diccionario bilingüe sigue cumpliendo un papel fundamental en el aprendizaje de una lengua extranjera porque, sobre todo en los niveles iniciales ${ }^{4}$, los estudiantes se sienten más cómodos y seguros comparando las estructuras léxicas y sintácticas entre su lengua materna y la lengua que cstán aprendiendo. Los resultados de varias encuestas publicadas recientemente (Corpas, 2001; Azorín \& Climent, 2003) muestran la primacía del diccionario bilingüe sobre los monolinguies de aprendizaje en el uso real que se hace del diccionario en el aula. Esta utilización está en relación con la competencia lingüístico-cultural del usuario, de manera que a mayor competencia lingüistica por parte de los estudiantes, menos uso del diccionario bilingüe porque ofrece escasa información sintáctica y pragmática que facilite la producción de enunciados (función codificadora) y mayor uso del diccionario monolingüe (Gelpi, 1997; Santamaría, 2000 y 2003).

Nuestro estudio se centrará en el examen de los diccionarios monolingües españoles de aprendizaje, en aquellos diccionarios elaborados para estudiantes no nativos. Hemos escogido los siguientes por ser los más conocidos y utilizados por los alumnos de nivel avanzado que estudian esta lengua:

- Diccionario Salamanca de la lengua castellana, Madrid, Santilland, 1996 (JSTEE)

- Diccionario para la enseñanza de la lengua española, Alcalá de Henares, VOX, 1995 (DIPELE)

4 Partiendo de los niveles establecidos en el Marco de Referencia Europeo, nos estamos refiriendo a los niveles A1, A2 y B1

5 Debemos precisar que la encuesta realizada por la profesora Corpas y su equipo de investigación (Corpas el alii, 2001) estaba dirigida a cstudiantes de Traducción e Interpretación de la Universidad de Málaga que, aunque tengan unas necesidades distintas a los estudiantes de longuas extranjeras, en cierto modo también podemos considerarlos como aprendices de una lengua extranjera, ya que un cstudiante de Traducción debe tener un buen conocimiento gramatical, discursivo y sociolingüístico de la lengua de la qque traduce. Por el contrario, los resultados de la encuesta realizada por Azorín y Climent (2003) en la Universidad de Alicante recogen las preferencias en el uso real de los diccionarios por parte de cstudiantes de español como lengua extranjera que acuden a dicha Universidad a aprender o perfeccionar su conocimiento dcl cspañol.

6 Aunque no es un diccionario elaborado exclusivamente para el aprendizajc del español como lengua extranjera y así lo indica en la Introducción (1996: $\mathrm{V}$ ): «este diccionario se dirige a todos los cstudiantes, sean a no extranjeros, que quicran mejorar su dominio de la lengua española», se utiliza también con este fin. 
- Diccionario de la lengua española para estudiantes de español, Madrid, Espasa, 2002 (DES)

- Diccionario de español para extranjeros, Madrid, SM, 2002 (DEE)

- Gran diccionario de uso del español actual, SGEL, 2001 (GDUEA)

El hecho de que sean obras didácticas implica que cstán concebidas para ayudar al usuario a aumentar y mejorar los conocimientos generales de la lengua que estudian y a intentar facilitar el uso activo de la lengua, ya que no sólo deben permitir la comprensión sino tambićn facilitar la producción de enunciados correctos. Estos objetivos afectarán a la estructura de la obra, tanto a la macroestructura, especialmente en el proceso de selección del léxico, como a la microestructura, en la selección y disposición del conjunto de informaciones que componen el artículo. De manera quc, como vienen señalando diversos autores (Rundell, 1998; Schafroth, 1998; Azorín, 2000), los rasgos que diferencian un diccionario monolingüe de tipo didáctico de otro común o general son:

1 Selección del léxico según las nccesidades de aprendizaje

2 Información sobre la pronunciación

3 Definiciones adaptadas al tipo de usuario

4 Control del vocabulario definidor

5 Ejemplificación abundante

6 Mayor presencia de información gramatical o sintáctico-semántica

7 Mayor presencia de unidades fraseológicas, especialmente de las colocaciones

8 Mayor presencia de información pragmático-comunicativa

9 Mayor presencia de información normativa

10 Mayor presencia de información cultural

11 Mayor presencia de información sobre las relaciones semánticas

En este trabajo nos vamos a centrar en la presencia de la información gramatical en el diccionario monolingüe de aprendizaje, ya que, a diferencia de los hablantes nativos que usan los diccionarios monolingües comunes, donde el lexicógrafo presupone una seric de conocimientos interiorizados, los hablantes no nativos precisan información explícita acerca de las propiedades morfológicas y sintáctico-semánticas que caracterizan las unidadcs léxicas, así como de las reglas que rigen su combinatoria y actualización en el discurso (Azorin, 2000).

\section{RELACIÓN LÉXICO-GRAMÁTICA EN EL PROCESO DE APRENDIZAJE}

2.1. Si hacemos un breve recorrido por la historia de la enseñanza de lenguas (Aquilino Sánchez, 1992; García Santa-Cecilia, 1996), comprobamos que a lo largo del siglo XX hemos asistido a diferentes propuestas metodológicas de enseñanza ${ }^{7}$ hasta llegar al Marco

$7 \quad$ A lo largo del siglo XX hemos asistido a diferentes propuestas de enseñanza: están las que se caracterizan por requerir del profesor un papel de dirección del proceso (método de gramática y traducción, método directo, método audiolingǘsicico, etc.); otras, surgidas en los 70 , hasadas en la importancia de las relaciones afectivas en el aula y en una pedagogía humanista (el aprendizaje comunitario de la lengua la vía silenciosa, etc.); y los enfoques comunicativas, que rompen con la idea de propuesta pedagógica acabada y plantean una aproximación a la enseñanza-aprcndizaje de cada lengua que se adapte a las necesidades de cada público. Podemos hablar de dos 
de Referencia Europeo, enfoque centrado en la acción, ya que concibe a los alumnos que aprenden una lengua como 'agentes sociales', es decir, como miembros de una sociedad que tienen que llevar a cabo tareas en unas detcrminadas circunstancias y en un entorno especifico. El Marco de Referencia Europeo describe el uso y el aprendizaje de lenguas como aquel que «comprende las acciones que realizan las personas que, como individuos y como agcntes sociales, desarrollan una serie de competencias, tanto generales como competencias comunicativas, en particular. Las personas utilizan las competencias que se encuentran a su disposición en distintos contextos y bajo distintas condiciones y restricciones, con el fin de realizar actividades de la lengua que conllevan procesos para producir y recibir textos relacionados con temas en ámbitos específicos, poniendo en juego las estrategias que parecen más apropiadas para llevar a cabo las tareas que han de realizar».

Sin olvidar la importancia de las competencias generales, nos interesa desarrollar el concepto de competencia comunicativa. Hemos pasado de una concepción de la lengua basada en el conocimiento de la gramática a una concepción donde el conocimiento gramatical de la lengua se une a la capacidad de usar esa lengua en situaciones concretas de manera adecuada. El dominio comunicativo comprendc varios subcomponentes ${ }^{8}$ :

- el lingüístico, que incluye los conocimientos y las destrezas léxicas, fonológicas y sintácticas.

- el sociolingüístico, que se refiere a las condiciones socioculturales del uso de la lengua.

- el pragmático, que tiene que ver con el uso funcional de los recursos linguísticos.

Por tanto, no es suficiente con la descripción de la lengua como sistema formal que sirve para la expresión de significado, es necesario tener la capacidad de utilizar ese sistema de forma adecuada en las diferentes situaciones comunicativas concretas.

Centrándonos ya en los aspectos lingüísticos, se establecen diversos elementos ${ }^{9}$ de los cuales nos interesa la competencia léxica, que se basa en el conocimiento del vocabulario

tendencias en los enfoques comunicativos: una, desarrollada lundamentalmente en Europa, a partir de los estudios de lingüística funcional y su aplicación a la enseñanza de lenguas (la teoría de los actos de habla, el análisis del discurso, la sociolingǘrstica, etc.) que dio lugar a los métodos nociofuncionales; y otra, que asranca de los estudios de psicología cognitiva norteamericana y de los trabajos sobre adquisición de lengua materna y segundas lenguas, ctc., que sustenta los enfoques naturales. Richards y Rodgers (2001) establecen la siguiente clasificación dentro de los cnfoques comunicativos:

- la enseñanza comunicativa de la lengua, cuyo origen se sitía en los cambios que tienen lugar en Gran Bretaña a finales de los sesenta.

el enfoque natural (Terrel!, 1977)

- el aprendizaje de la lengua conperaitvo

- el enjogue de los contenidos

- el enfoque por tareas

- la siluación postmétodo

8 Para más información, véase capílulo 2 de Marco de referencia europeo.

9 Dc acucrdo con la clasificación realizada en el Marco de referencia europeo, la competencia lingüistica está formada por varios componentes a partir de los cuales se pueden articular y formular enunciados bien formados y significativos. Son: la competencia léxica; la competencia gramatical, conocimiento de los rccursos gramaticales de una lengua y la capacidad de utilizarlos; la compeiencia semóntica, conocimiento y destreza de los componentes del significada y de su organización; la competencia fonológica, conocimiento y destreza en la percepción y la producción de los sonidos; la competencia ortográfica, conocimiento y destreza en la percepción y producción de los símbolos de que se componen los textos escritos y la competencia ortoépica, conocimiento y destreza para alcanzar una promunciación correcta partiendo de la forma escrita. 
de una lengua y la capacidad de utilizarlo. Está formado por elementos léxicos y elementos gramaticales.

En cuanto a los elementos léxicos habrá que tener en cucnta no sólo las unidades léxicas simples o univerbales (mesa, sol, casa) sino también las complejas o pluriverbales quc comprenden diversos tipos: fórmulas fijas que son necesarias para las distintas funciones comunicativas (encantado de conocerle, en resumen), expresiones idiomáticas (perder la cabeza, pagar los platos rotos), combinaciones sintagmáticas fijadas por el uso (cometer un asesinato, herido leve).

En cuanto a los elementos gramaticales nos referimos a clases cerradas como artículos, cuantificadores, demostrativos, pronombres, prcposiciones, etc.

Todas estas unidades se organizan en función de las categorías, los elementos, las clases, las estructuras, los procesos y las relaciones que contraen entre sí para expresar y transmitir sentido; esto es, el alumno debe aprender a organizar, estructurar las distintas piezas léxicas de quc dispone para expresar significados. De manera que en el proceso de aprendizaje de una lengua, ambos conocimientos, el léxico y la gramática, están unidos de manera indisoluble. Tan inútil es conocer el vocabulario de una lengua pero no saber estructurarlo y organizarlo como conocer las normas y reglas de organización morfosintáctica y no conocer el léxico de esa lengua.

Esta conjugación de conocimientos léxicos y gramaticales debe quedar reffejada en los distintos materiales e instrumentos que utilizan los estudiantes durante su proceso de aprendizaje, cntre los que destaca el diccionario. No estamos ante la misma estructura sintáctica en enojar a alguien que en enojarse con alguien/algo, pues de la misma manera que existe una relación entre el significado de una palabra y sus propiedades semánticas, debemos aceptar que los entornos sintácticos ponen de relieve propiedades semánticas y pueden diferenciar acepciones haciéndolas más claras para los usuarios (Azorín \& Martínez Linares, 1994-95: 230). De modo que esa distinta construcción sintáctica que implica argumentos distintos debe quedar reflejada en las obras que se centran en la rccopilación del léxico, las cuales no deben ofrecer únicamente la forma y el significado de las piezas léxicas, sino que también deben pcrmitir organizarlas y usarlas de forma correcta.

A pesar de los innumerables artículos que tratan la relación existente entre gramática y diccionario (Rojo, 1997; Alvar Ezquerra, 1993; Bargalló, 1999, etc.), la tradición lexicográfica española no ha dedicado una cspecial atención a este aspecto. Ha sido en los últimos años, con el desarrollo de la enseñanza de lenguas, cuando se ha visto la necesidad de elaborar diccionarios que aporten este tipo de información para ayudar al usuario en las funciones de codificación de enunciados. El resultado ha sido que aquellos diccionarios didácticos elaborados para hablantes no nativos aportan - o al menos deberian aportar - más datos acerca de la información gramatical, pues son estos usuarios los que mayores carencias de este orden presentan, sobre todo morfológicas y sintácticas.

2.2. De acuerdo con lo visto en el apartado anterior, el desarrollo de la competencia léxica no sólo se relaciona con la cantidad de vocabulario que se aprende sino también con la organización cognitiva y la forma en que se almacenan esos conocimientos.

No debemos olvidar que una palabra, además de ser portadora de significado, realiza una función dentro de la oración de la que forma parte. El conocimicnto de una palabra es 
un proceso complejo y gradual en el que se aprende no sólo la forma y el significado sino también una intrincada red de relaciones formales y semánticas entre esa unidad y otras. De manera que, cuando adquirimos el conocimiento de una palabra, conoccmos la forma, el significado y el uso de la palabra.

Veamos cómo se produce ese proceso cognitivo y las relaciones que podemos establecer entre el léxico, la semántica y la gramática. La organización del lexicón se basa en un conjunto de procesos que permiten adquirir los signos linguísticos y almacenarlos de manera que estén disponibles para ser recuperados durante el proceso comprensivo del input y durante el proceso creativo de la producción, output. Según Aitchison (1994), los niños adquieren su vocabulario mediante tres tareas diferentes interconectadas: etiquetan (ponen una forma a un concepto); empaquetan (categorizan las distintas formas agrupadas según la clase a la que pertenecen) y construyen (realizan conexiones de diferentes niveles entre las palabras). Una vez que se ha aprendido una palabra, se almacena en el lexicón con la información categorial pertinente para aplicar las reglas gramaticales correspondientes a esa clase. Así pues, cuando se aprende una palabra como comer se almacena en el lexicón y se le pone la etiqueta de [+ verbo]. Esta categorización le permitirá a la pieza léxica someterse a todas las reglas de flexión propias de los verbos de segunda conjugación, de mancra que un alumno asignará el mismo significado léxico, con las especificaciones propias de persona, número, tiempo, modo y aspecto, a formas como comian, comeremos, comió, etc. Pero todavía hay más información. En la estructura semántica y conceptual de comer, el aprendiz reconoce dos argumentos: uno correspondiente a lo que come y otro correspondiente al que come. A partir de esta red argumental léxico-semántica obtenemos toda la información necesaria para proyectar la estructura sintáctica de la oración y organizar una estructura transitiva en la que se asigna la función de sujeto sintáctico al agente, al que come y función de objeto directo a lo que se come. En Juan come fruta, los estudiantes entienden quién come y qué come, gracias a que procesan la estructura dándole la función sintáctica correspondiente a cada sintagma nominal.

Por tanto, cuando aprendemos una palabra adquirimos todos los datos gramaticales que esa palabra conlleva. Por ejemplo, sabemos que la forma come es un verbo y como tal la tratamos al agregarle un sufijo flexivo -s, en comes, que interpretamos como una marca gramatical de segunda persona singular. Sin embargo, si añadimos una $-s$ a niño, la información gramatical que procesamos para el sufijo $-s$ es la marca de plural. Cuando almacenamos una nueva palabra la etiquctamos como nombre, verbo, adjetivo, etc. Para saber si debemos interpretar una palabra como verbo o como nombre debemos atender siempre a la información que nos proporciona cl contexto lingüístico en el que aparece. Así en Pon la coma en esta frase, sabemos que coma es un nombre frente Quiero que coma más, sabemos que es una forma del verbo comer.

Como hemos visto conocer una palabra es un proceso cognitivo complejo ya que una palabra, además de ser portadora de significado, desempeña una función dentro de la oración de la que forma parte. Los valores semánticos y las relaciones gramaticales son elementos que están unidos de forma inscparable y esta relación debe quedar recogida en los diccionarios. Esta concepción del diccionario fue iniciada por Cuervo (1886-1994) que consideraba necesario que los diccionarios aportaran no sólo información semántica de la unidad sino también su caracterización gramatical y sus particularidades construccionales y combinatorias. Sin embargo, este tipo de información no ha estado presente tradicionalmentc en los 
diccionarios del español (Rojo, 1997; Azorín y Martínez Linares, 2001). Si bien es cierto, que en los últimos años, los autores de diccionarios didácticos introducen en sus repertorios apéndices gramaticales y proporcionan información acerca de las características morfológicas y sintácticas de las palabras y también de los valores de significado asociados a las diferentes construcciones en que puede encontrarse ese elemento.

Volviendo a los diccionarios didácticos destinados a estudiantes no nativos, qué duda cabe que esta información resulta imprescindible para sus usuarios. Así pues el diccionario monolingüe español discñado y elaborado para el aprendizaje de esta lengua es un instrumento imprescindible para todo aquel usuario que quiera conocer el significado y el uso de las unidades léxicas del español. Nos encontramos ante un texto que incorpora información completa relativa a cada una de las entradas; esto cs, la sintaxis particular de cada unidad léxica (Ahumada Lara, 2003). Nos proporcionan información sobre la pronunciación, la morfología, la sintaxis, el significado y el uso de la palabra así como sus relaciones léxicas con otras (Rizo Rodríguez, 1991). Así pues, el patrón común de las entradas lexicográficas, en este caso referidas a los verbos, en los diccionarios monolingües de aprendizaje del español es el siguiente:

- lema, con indicación de la división silábica

- pronunciación

- categoría gramatical

- definición o acepciones

- ejemplos

— información sintagmática

- información paradigmática

- observaciones gramaticales

A partir de cste punto, muestro objetivo es constatar la presencia de información de orden gramatical que figura en diversas partes del diccionario monolingüe de aprendizaje (preliminares, macroestructura, microestructura). Como ya hemos ido señalando, en este trabajo focalizamos nuestra atención en la categoría gramatical del verbo porque es uno de los elcmentos en los que más claramente se produce esa interrelación entre gramática y diccionario, ya que los distintos valores de significado que puede adquirir esa forma vcrbal están asociados a las diversas construcciones en que puede cncontrarse ese elemento.

En lo que sigue vamos a analizar, por un lado, el tipo de información que sobre la conjugación verbal ofrecen los diccionarios didácticos del español en las partes introductorias; por otro, el lugar y la forma en que se presenta la información verbal en estos repertorios léxicos. También observaremos el tratamiento que se lc da al verbo como categoría gramatical que mayor atención recibe desde este punto de vista debido a su función como núcleo en la oración del que dependen otros elementos para crear una estructura oracional y analizaremos aspectos como la categoría y subcategoría gramatical, la información sintáctica como el régimen preposicional, el contorno de la definición y los ejemplos. 
3. LA INFORMACIÓN GRAMAIICAL SOBRE I.A FLEXIÓN VERBAL EN LOS DICCIONARIOS MONOLINGUUES DE APRENDIZAJE

3.1. Con respecto a la información de tipo gramatical que aparece en los preliminares del diccionario se observa de manera generalizada que los diccionarios estudiados incorporan en los prólogos datos que permiten saber qué tipo de información vamos a encontrar en el interior del artículo a propósito de la conjugación verbal. Además es frecuente la presencia de una guía que aclara al usuario cómo consultar y usar el diccionario.

Por otro lado, estas obras destinadas a servir de ayuda en el aprendizaje de una lengua extranjera son conscientes de que el diccionario es la obra a la que primeramente acude el usuario para aclarar dudas de carácter gramatical. De ahí que en todos ellos figure al final de la obra ${ }^{10}$ un apéndice que recoge cuestiones gramaticales como por ejemplo los modelos de la conjugación verbal en español. Generalmente, en estos apéndices finales se presentan los verbos siguiendo el orden alfabético, lo cual facilita el manejo y la búsqueda de una determinada forma verbal a los destinatarios de cste tipo de obras que suelen tener dificultades principalmente a la hora de flexionar un verbo, pero también a la hora de llegar hasta el modelo o representante canónico de la forma flexionada que encuentran en un texto. En primer lugar, el usuario halla los modelos de conjugación regular y seguidamente, aparecen los patrones irregulares ${ }^{11}$. Pero hay algunos diccionarios que utilizan otro tipo de clasificación distinta a la alfabética. Se basan en una ordenación sistemática de los verbos irregulares del espaniol, lo que permite al usuario clasificar los verbos irregulares según el tipo de irregularidad que presentan facilitando el aprendizaje de los verbos irregulares por analogía con los verbos modelos. Es el caso del DIPELE y el GDUEA que realiza una clasificación de los verbos irregulares según presenten alteraciones acentuales, irregularidades ortográficas o verbos irregulares propiamente dichos. El DEE tampoco utiliza la ordenación alfabética pues presenta los modelos de conjugación verbal a partir de una clasificación de los verbos diferenciando verbos regulares e irregulares, verbos auxiliares, verbos pronominales, verbos en pasiva, verbos defectivos ${ }^{12}$.

A modo de resumen, presentamos en el cuadro siguiente los distintos tipos de información gramatical, referida a la conjugación verbal, que ofrecen los diccionarios revisados en los preliminares de la obra o como apéndice final.

\begin{tabular}{|c|c|c|c|c|c|}
\hline & DSLE & DIPELE & DES & DEE & GDUEA \\
\hline Prólogo & + & + & + & + & + \\
\hline Guía usuario & & + & + & + & \\
\hline ales en el inte & & & & & \\
\hline dice gramatical final & + & - & + & + & + \\
\hline
\end{tabular}

Cuadro 2. Localización de información sobre flexión verbal

10 A excepción del DEE que incluye los modelos de conjugación verbal junto a la entrada verbo en el cuerpo del diccionario.

11 El DES incluye los verbos modeles de conjugación en orden alfabético pero marca en color gris aquellos verbos cuya irregularidad se basa en aIguna alteración orlográfica o acentual. El DSLE inchye además un índice alfabético de los verbos irregulares del español con una remisión numérica que nos lleva al verbo modelo y señala al final de estc una lista de verbos que se conjugan como aquel.

12 Son estos diccionarios, el DEF, el GDUEA y el DIPELE, los que incluyen, además de los modeios de conjugación, un resumen gramatical del verbo sobre las desinencias verbales, tipos de verbo, etc. 
3.2. En cuanto al modo de presentación de la flexión verbal, es obvio que el usuario del diccionario no encuentra en la nomenclatura de las obras lexicográficas todas las formas posibles del vocabulario, sino que cada paradigma aparece representado por un solo elemento, lo cual obliga al aprendiz de esa lengua a un proceso de reducción morfológica desde que ve en un texto una palabra cuyo significado desconoce, hasta que halla en el diccionario la entrada del artículo correspondiente. Este procedimiento requiere por partc del hablante un buen conocimiento gramatical de la lengua, conocimiento del que no siempre disponen los aprendices de una lengua extranjera ${ }^{13}$.

Tras el análisis descriptivo de las formas verbales que figuran como entradas en los diccionarios, podemos decir que se observa la tendencia de no incluir las variantes léxicas irregulares de los verbos como parte de la nomenclatura de los diccionarios. No obstante, y especialmente en el caso de los diccionarios de aprendizaje, creemos que la selección de unidades verbales debe estar abicrta a cualquier forma irregular, rara o dificil de interpretar por cl hablante y de relacionar con el lema. Cada forma léxica de un verbo es una palabra morfológicamente compleja constituida por morfemas segmentables de clase y significado diferente: raíz + desinencias o morfemas verbales flexivos. Si nos encontramos con una forma verbal irregular, que dificilmente el alumno puede relacionar con el representante del paradigma, es mejor situarlo como entrada en el diccionario. Si nos fijamos en este aspecto, se observa que sólo el DEE incluye formas verbales irregulares como entradas tales como anduvo (de andar), cupe, quepo (de caber), cayó (de caer), fui (de ir), sepa (de saber), etc.

Las explicaciones dc estos elementos verbales irregulares se realizan en metalengua de signo, porque no representan un paradigma, sino que son formas de esos paradigmas, variantes del habla, cuya explicación del contenido debe buscarse bajo el lema correspondiente; esto es, nos envían a la forma canónica, bajo la cual se da la definición. Sin embargo, a pesar de las ventajas que la inclusión de formas irregulares podría tener para los estudiantes extranjeros, se adopta la postura de que el diccionario no es una gramática y, por lo tanto, no deben figurar como parte de la macroestructura variantes gramaticales u ortográficas; la mayoría de los diccionarios didácticos estudiados las incluyen como observaciones o notas complementarias al final del artículo.

Más complejas son las decisiones a propósito de la inclusión de otros lemas verbales como los participios. En lo referente a los participios regulares, los diccionarios analizados optan por no incluir aquellos que sólo actúan como verbos, ya que su significado es fácilmente deducible, tales como apreciado, compadecido, enojado, tenido, etc.; sin embargo, si esos participios regulares toman otros valores que los estrictamente verbales - normalmentc adquicren la categoría de adjetivo o sustantivo - como por ejemplo acabado, dejado, sentido, tomada, etc., los diccionarios muestran dos posiciones:

a) Algunos indican que se trata de un participio con otros valores categoriales, lo que no es habitual en los diccionarios estudiados.

13 Si el aprendizaje del representante del paradigma se realiza de manera defectuosa, el alumno nunca podrá legar a ser un buen usuario del diccionario; por tanto, los profesores de lengua no debemos dar por sabido que el alumno es capaz de descifrar esa forma canónica de las palabras usadas en los tex tos, puesto que no siempre es así, especialmente en fase de aprendizaje de una lengua. De hecho, a través de los resultados de varias encuestas sobre el uso del diccionario por parte de los escolares ( $\Lambda$ zorín, 2000; Candalija \& Marimón, 2000; Santanaría, 2000) se concluía que una de las principales deficiencias que encuentra el alumno de ESO y Secundaria en su diccionario es que no siempre encuentra la palabra que busca y esto se debe en muchos casos a que no sabe buscarla. 
b) La mayoría no hacen referencia a su valor verbal inicial, sólo indican su categoria de adjetivo o de sustantivo.

Por lo que respecta a los participios irregulares, caben dos consideraciones: por una parte, incluir aquellos participios irregulares dado que es una información importante para conjugar de forma adccuada los ticmpos compuestos; por otra, incluir sólo aquellos participios irregulares que adquieren otros valores, además del verbal. Los diccionarios estudiados optan porque aparezcan todos los participios irregulares, ya sea formando parte de la nomenclatura como por ejemplo abierto, escrilo, hecho, puesto, etc. - generalmente cuando el participio adquiere otros valores-, ya sea en el interior del artículo, especialmente cuando no presenta ningún cambio categorial como sido, vuelto, etc.

En el siguiente cuadro se resume de forma gráfica las distintas formas verbales que se hallan formando parte de la nomenclatura de los diccionarios didácticos monolingües revisados.

\begin{tabular}{|c|c|c|c|c|c|c|}
\hline & & DSLE & DIPELE & DES & DEE & GDUEA \\
\hline $\begin{array}{l}\text { Lema verbal } \\
\text { fundamental }\end{array}$ & Infinitivo & + & + & + & + & + \\
\hline \multirow[t]{4}{*}{$\begin{array}{c}\text { Otros lemas } \\
\text { verbales }\end{array}$} & $\begin{array}{c}\text { Formas irregulares } \\
\text { de los tiempos } \\
\text { personales }\end{array}$ & & & & + & \\
\hline & $\begin{array}{c}\text { Participios regulares } \\
\text { no verbales }\end{array}$ & + & + & + & + & \\
\hline & $\begin{array}{c}\text { Participios irregulares } \\
\text { verbales }\end{array}$ & + & & & + & + \\
\hline & $\begin{array}{c}\text { Participios irregulares } \\
\text { no verbales }\end{array}$ & + & + & + & + & + \\
\hline
\end{tabular}

Cuadro 3. Formas de la fexión verbal en los diccionarios didácticos

3.3. En cuanto a la información de orden gramatical contenida en el interior del artículo lexicográfico de los diccionarios monolingücs cspañoles de aprendizajc, nos fijarcmos en aquellos datos de orden morfológico y sintáctico que contribuyen a que los alumnos de español como lengua extranjera puedan sacar mayor provecho y rendimiento de su diccionario. Esto es, sabemos que los diccionarios didácticos actuales del español han mejorado considerablemente este aspecto gracias a la investigación metalexicográfica y al avance de la enseñanza de español como lengua extranjera. Pero, ¿ayudan realmente a los alumnos no nativos a entender los cambios de significado que se producen debido a los cambios de construcción sintáctica? ¿Sirven al alumno para poder producir enunciados correctos desde el punto de vista gramatical atendiendo a la información morfofuncional que aportan?

Tradicionalmente, la lexicografia, tanto monolingüe como bilingüe, ha visto el diccionario como una herramienta útil para la descodificación. En cambio, su función como instrumento de codificación quedaba reducida a algunas notas u observaciones gramaticales como la categoría y subcategoría gramatical, los cambios de categoría y alguna información sobre 
el régimen preposicional o cl contorno en el caso de los verbos u otras categorías como los adjetivos (Ahumada Lara, 2003: 89).

Para un diccionario escolar que cuenta con el conocimiento implícito e intuitivo de los hablantes nativos de esa lengua, aunque estén en fase de aprendizaje, puede resultar suficiente con esta información gramatical. Por cl contrario, el hablante no nativo, que aprende de forma consciente la gramática de esa lengua extranjera, precisa de más datos y observaciones de carácter gramatical $\mathrm{y}$, además, esta información debe ser adecuada al nivel do conocimiento de la lengua que está aprendiendo.

Como ya comentábamos en las primeras páginas de este trabajo, el estudiante de una lengua extranjera prefiere utilizar un diccionario bilingüe para entender el significado de una unidad léxica que encuentra en un contexto, especialmente en los niveles iniciales; pero cuando tiene un cierto dominio de esa lengua, ya no es suficiente con la mera transcodificación que ofrecen los diccionarios bilingües, sino que prefiere las definiciones en contexto, porquc quiere ver cómo se usa esa unidad, de manera que busca información más precisa. Asi, el diccionario debe especificar la sintaxis particular de cada unidad, si se construye con sujeto animado o inanimado, los tipos de argumentos verbales, etc.

Los diccionarios didácticos del español destinados a hablantes no nativos son conscientes de esta necesidad por parte de sus usuarios y así lo indican on los preliminares de la obra. Así por ejemplo, en el prólogo del diccionario Salamanca podemos leer:

comparte con otros diccionarios generales de la lengua la información enciclopédica habitual, pero, sobre todo, pretende con sus observaciones morfológicas y sintácticas ayudar a los usuarios para que incorporen activamente a su léxico las palabras consultadas y las empleen con seguridad en la vida cotidiana, tanto oralmente como por escrito. ${ }^{14}$

Observaciones de este tipo se pueden ver en los preliminares del resto de diccionarios analizados, lo que viene a reflejar la preocupación de la lexicografía didáctica monolingiie de incluir información de carácter morfofuncional que ayude a un uso activo de la lengua.

El primer dato gramatical que ofrecen estos diccionarios, como viene siendo habitual ${ }^{15}$ en los diccionarios del español, es la categoría y subcategoría gramatical (transitivo, intransitivo, pronominal) ${ }^{16}$. Lo más usual es indicar si un verbo es transitivo o intransitivo o si tiene un uso pronominal, es decir, la información se reduce a si el verbo puede llevar o no objeto directo, pero no se informa al usuario de los diferentes complementos argumentales del verbo distintos del complemento directo. No es suficiente con saber si un verbo, elemen-

\footnotetext{
14 El subrayado es nuestro.

15 Siguiendo la tradición lexicográfica española, cualquier diccionario del cspañol prescnta junto a la cntrada la correspondiente anotación sobre la categoría gramatical. Esta información se presenta mediante unas abreviaturas que se explican al principio de la obras y suelen ser de uso general. Este tipo de información es necesaria y útil para cl uso corrccto de las palabras y a través de las abreviaturas de las que se vale el lexicógrafo para transmitirlas de forma clara y sucinta. Ninguno de los diccionarios analizados ofrece una explicación o cuadro que resuma las distintas clases de verbos que existen en español, pero una rápida observación del conjunto de abreviaturas empleadas por cada uno de los diccionarios nos va a permitir observar cuáles son las categorías y subcategorías utilizadas en estas obras.

16 A excepción del DES que indica la categoria gramatical de verbo mediante la abreviatura $v$ y la subcategorfa de verbo pronominal (v. prnl), tendencia que, aunque no se justifique en el prólogo, viene observándose en los diccionarios de la editorial SM. De manera que las variaciones de construcción se observa a través de la definición o los ejemplos.
} 
to clave en la organización oracional, es transitivo o intransitivo. Se necesitan además otras informaciones como el número de argumentos, el régimen preposicional o el tipo de entidades que selecciona como argumento (objetos, eventos, animados, inanimados), etc.; esto es, habrá que tener en cuenta las diferentes estructuras argumentales para describir las distintas acepciones de significado del verbo. (Azorín y Martínez Linares, 1994-95: 227 y sig.)

En cuanto a las construcciones pronominales ${ }^{17}$, los diccionarios de aprendizaje suelen indicar la coexistencia de ambas construcciones mediante la indicación tr.prnl. Esta marcación puede servir en casos en los que no se produccn cambios en la significación pero no en aquellos en los que el paso de la construcción transitiva a la pronominal conlleva un cambio de significado. Pcro, aunque el diferente entorno sintáctico no implique un cambio de significado, en el cuerpo del artículo, ya sea en la definición o mediante un ejemplo o como observación gramatical, deben quedar delimitadas todas las posibles estructuras sintácticas en que puede aparecer esa unidad.

DES compadecer tr.-prnl. 'sentir /alguien/ lástima o pena por la desgracia o el sufrimiento (de otra persona): Compadezco a esa pobre mujer que no tiene ni un techo donde dormir. MOD. agradecer. Como prnl. se construye con de: Me compadezco de mi, por mi mala sterte.

En principio, parece que los diccionarios de aprendizaje de español se preocupen por recoger los diferentes entornos sintácticos de cada pieza verbal. Si hacemos un análisis más pormenorizado, se observa que este tipo de diccionarios se han hecho eco de los avances de la teoría lexicográfica indicando cl régimen preposicional o los elementos del contorno, poniendo más ejemplos, etc., pero sigue sin ser habitual la inclusión de otro tipo de información gramatical. Veámoslo con algunos ejemplos concretos.

Supongamos la existencia de un estudiante extranjero que necesita consultar en el diccionario el verbo anteriormente mencionado: compadecer. Se trata de un verbo que presenta régimen preposicional exclusivo con de e indica emoción o sentimiento (Cano Aguilar, 1999: 1845). A partir de los diccionarios de aprendizaje revisados, la información que obtiene el usuario es que se trata de un verbo transitivo-pronominal con diferencias construccionales que no implican variación de significado. Pero, si ese estudiante quiere usar activamente el verbo compadecer, dificilmente obtendrá enunciados satisfactorios. Por ejemplo,

DSLE compadecer v. tr./prnl. 'sentir <una persona> pena por la desgracia [dc otra persona]: Se compadeció del infeliz

DIPELE compadecer tri-prnl. [algo, a alguien] Sentir pena o dolor por quienes sufren: todos compadecian a la viuda y trataban de consolarla; compadezco a Alicia por su mala suerte, :pobre Ángel, me compadezco de él!

En primer lugar, la definición recoge sólo uno de los posibles entornos sintácticos en los que puede aparecer esa unidad: el transitivo, mientras que el cjemplo atiende a la construcción pronominal, to que podria confundir al usuario del diccionario que carece de dominio idiomático. En segundo lugar, de acuerdo con esta información sobre los elementos sintác-

17 El diccionario de Aquilino Sánchez, GDUEA, lama a estas construcciones REFL (-sc). 
ticos-semánticos del vcrbo compadecer, el complemento que recibe la acción sólo puede ser una persona (Juan compadece a su amigo por la muerte de su esposa / Juan se compadece de su amigo). Sin cmbargo, cs posible que el argumento exigido por el verbo compadecer en uso pronominal sea no animado (Juan se compadece de su mala suerte / Hasta que alguien se compadeció de su locura). ¿Como puede deducir un usuario, que tiene un desconocimiento del idioma que está aprendiendo, que el verbo compadecer en la construcción pronominal admite un argumento inanimado? Si nos fijamos en los diccionarios revisados, sí consta esta diferenciación entre objeto de persona o de cosa en DIPELE, pero sin especificar el tipo de estructura en que es posible la utilización de un objeto inanimado y como observación gramatical al final del artículo en el DEE (Constr. Compadecerse DE algo).

En segundo lugar, en relación con el verbo compadecer hay otro uso pronominal que rige una preposición distinta de la preposición de. En este caso el cambio de preposición sí que implica un cambio de significado: compadecer con 'estar de acuerdo', acepción con poco uso en el español actual y que sólo figura en el diccionario de GDUEA. ${ }^{18}$ Cabría preguntarse sobre la necesidad de incluir esta acepción poco frecuente en un diccionario de uso del español actual dirigido además a estudiantes no nativos.

Consideremos ahora otro verbo como enojar. Se trata de un verbo transitivo y pronominal que implica una relación mutua de carácter afectivo el cual presenta régimen exclusivo con la preposición con (Cano Aguilar, 1999: 1846). Aparece en construcciones como:

\section{Su falta de madurez enoja a su padre enormemente \\ Si no te portas bien, enojarás a tus padres \\ Se enoja con nosotros / con la falta de justicia}

A partir de estos enunciados podemos determinar la estructura sintáctica del verbo enojar. Se trata de un verbo que en construcción transitiva puede llevar un sujeto animado $\mathrm{o}$ inanimado (algo o alguien) y el argumento que exige es siempre animado (a alguien), estructura argumental que se recoge en la mayoria de los diccionarios analizados. Por ejemplo, DES enojar tr. y prnl. Enfadar o molestar mucho /alguien o algo/ (a una persona), causar /algo o alguien/ enojo (a una persona): ¿No te habrás enojado por esa bobada? En cuanto a la consirucción pronominal el sujeto sólo puede ser animado (alguien) y exige un complemento preposicional con el rasgo semántico de [+animado] o [-animado] regido por la preposición con (con alguien / con algo), construcción también recogida en los diccionarios analizados, pero sin indicar el carácter o entidad del argumento. El GDUEA indica que la forma pronominal es enojarse con/contra y en el DSLE, nos muestra la preposición que rige la forma verbal pronominal a través de los ejemplos marcada en negrita (se enoja por cualquier tonteria. Te enojaste innecesariamente con los amigos de tu padre). Ni contra ni por son preposiciones exigidas por el verbo sino partículas que introducen argumentos circunstanciales de causa u otros valores y fácilmente sustituibles por otras preposiciones o locuciones prepositivas como a causa de, debido a, etc.

Aunque cl diccionario no sea una gramática, no puede situar en el mismo nivel a aquellos complementos verbales introducidos por preposición exigida por el verbo tanto desde el punto de vista sintáctico-semántico como formal y aquellas expresiones que sitúan espa-

18 Hcmos hallado tambićn csta accpción en el Diccionario de español actual de Seco (1999), pero en éste último también está restringida a un uso literario. 
cio-temporalmente la acción, proceso o estado o indican modo, instrumento, etc., también complementos preposicionales exigidos por el verbo, pero que no serían de régimen pues la preposición sirve para caractcrizar semánticamente la relación del sintagma que introduce respecto del elemento que rige y por tanto puede alternar con otras de valor similar, ya que lo que cl verbo exige es un complemento determinado, pero no una forma especifica de ese complemento. No es el mismo tipo de complemento preposicional Hablaron de politica toda la noche que Residen en/cerca de/fuera de la ciudad, puesto que la preposición del complemento de la primera frase no es intercambiable con otras y se considera una expansión del verbo muy semejante a la de un objeto directo (Cano Aguilar, 1999: 1809 y sig.).

Si el estudiante extranjero quierc obtcner estas diferencias de construcción a partir de la información sintáctico-semántica que le ofrecen los diccionarios analizados, difícilmente podrá llegar a producir enunciados correctos desde el punto de vista gramatical. Por ejemplo, en el caso del DEE no hay información acerca de la categoría gramatical del verbo, lo que en principio podría ser un dato prescindible para el hablante no nativo, pero de lo que no puede prescindir es de información sobre las características sintácticas del verbo, siendo como es un diccionario de reciente publicación.

e-no-jar v. Causar o sentir enojo: Tu falta de educación me enoja. Se enojó con nosotros porque no la esperamos.

Otros diccionarios como el GDUEA no diferencian los elementos significativos de los elementos del contorno de la definición y no indica el régimen preposicional ni en la definición ni en el ejemplo.

c-no-jar tr Causar enojo, enfado, molestia o fastidio a alguien: La polémica ha enojado a los componentes del grupo. También se usa como REFL(-se): Ella se choja cuando no lavas los platos.

Si nos acercamos al diccionario DSLE, que es el diccionario donde la información sobre la sintaxis particular de cada unidad y sus rasgos de construcción vienen mejor desarrollados, observamos que separa la acepción transitiva de la pronominal y, sin embargo, no hay cambio de significado, sólo diferente construcción sintáctica:

enojar $v$ tr 1 . Causar <una persona o una cosa> enfado a [una persona]: La entrenadora se enoja si el equipo no funciona. 2. Causar <una persona o una cosa $>$ molestias o disgustos a [una persona]: Las esperas me enojan mucho. // v. prnl. 3. Mostar <una persona > enfado por una cosa: Se enoja por cualquier tonteria. Te enojaste innecesariamente con los amigos de tis padre.

Otra información necesaria para que el usuario de estas obras pueda formular enunciados correctos en la lengua que está aprendiendo es establecer los diferentes tipos de entidades de los argumentos exigidos por el verbo. Supongamos que un estudiante extranjero de español se encuentra con las oraciones siguientes:

He acabado los deheres

El partido acaba/se acaba a las cinco

Se ha acabado el azúcar 
¿Puede llegar un estudiante extranjero a establecer qué diferencias sintáctico-semánticas tiene el verbo acabar en las construcciones anteriores? ¿Está esta información recogida cn los diccionarios didácticos?

Analicemos en primer lugar esas oraciones. En el primer caso, el verbo acabar cs un verbo transitivo que rige objeto directo (de cosa) y sujelo animado (de persona). En la segunda oración el verbo acabar tiene un uso intransitivo con un sujeto que debe ser un sustantivo de carácter eventivo (fiesta, función, película, elc.) que implica un suceso con un principio y un final (Cano Aguilar, 1981: 230). Esta estructura intransitiva admite la forma pronominal con se. Por el contrario, cuando el sujeto no es un nombre de acontecimiento, sino un sustantivo, generalmente no contable (azucar, agua, café, arroz, etc.) que indica una cantidad que se extingue o agota, sólo admite la construcción pronominal y con sustantivo determinado ( ${ }^{*} \mathrm{Ha}$ acabado el azticar).

Esta información debería estar recogida en la definición del verbo o a través de los cjemplos. Si el estudiante extranjero busca el verbo acabar en los diccionarios revisados, difícilmente podrá llegar a establecer esta diferenciación y, por tanto, no podrá utilizar correctamente dicho verbo. Únicamente el diccionario DSLE realiza esta distinción en las acepciones que se dan en el verbo acabar, pero sin establecer el tipo de entidad del argumento:

acabar $v$. intr. / prnl. 7 Llegar <una cosa> a su fin: Las clases se acaban hoy. La pelicula acaba bien. 8 Gastarse <una cosa> totalmente: Se ha acabado la cerveza. Se ha acabado el vino. Se acabaron las entradas.

Veamos otro ejemplo. El verbo comer puede aparecer formando parte de las siguientes construcciones oracionales con la acepción 'tomar <una persona> [alimentos]'. Los hablantes nativos conocemos de forma intuitiva que el uso impersonal necesita un sujeto indeterminado o cuantificado ( $E_{n}$ China se come arroz / En China se come mucho arroz $/^{*}$ En China se come el arroz); por el contrario, cuando está presente cl sujeto animado, la construcción transitiva exige la presencia de un objeto directo indeterminado (Juan come arroz todos los dias / *Juan come el arroz todos los dias) frente al uso pronominal que precisa de un objeto determinado (Juan se come el arroz / * Juan se come arroz).

Estos cambios en la construcción sintáctica deben estar recogidos en los diccionarios dirigidos a hablantes no nativos. Sin embargo, si analizamos los diccionarios de estas características, comprobamos que esta diferenciación no está recogida en ninguno de los diccionarios analizados.

Otro de los problemas de construcción por el que muchos usuarios consultan estos diccionarios es para saber si un determinado clemento rige o no preposición. Con respecto a esta información se presta especial atención a los verbos, sobre todo aquellos en los que el cambio estructural provoca un cambio de significado. No obstante, la prescncia o no del complemento preposicional puede alterar la estructura sintáctica del enunciado pero ello no tiene porque suponer un distinto valor sintáctico-semántico en el verbo. Por ejemplo, el verbo atender es un tipo de verbo que muestra oscilación entre complemento de régimen con a y objeto directo (Cano Aguilar, 1999: 1822): No atendió nuestras preguntas / No atendió a muestras preguntas. El diccionario Salamanca sí recoge el carácter opcional de la preposición en la estructura transitiva a través del ejemplo. 
DSLE atender v. tr./ intr. 1. Dar <una persona> una acogida favorable a [una petición]: Atendió (a)muestras súplicas. Suele atender nuestras indicaciones

Otros diccionarios lo expresan a través de información complementaria entre parćntesis (acotaciones de uso) como el DIPELE o el GDUEA:

atender 1. tr.-intr. [algo, a algo/alguien] Poner atención; aplicar el entendimiento a un asunto: es importante $\sim$ en clase; el perro atiende a la yoz de su dueño

atender tr intr. 1. (Con $a$ ) Aplicar una persona la mente o los sentidos para captar lo que se dice o para adquirir conocimientos de lo que ocurre o se presenta dclante de ella: El profesor se ha quejado de que no atiendes a lo que explica en clase 2. (Con a) Tener alguien en consideración una cosa (consejo, opinión, etc.), dejando que afecte a su comportamiento o forma de actuar: Me irrita que no atiendas a mis consejos y directrices [... ]

Como hemos ido viendo, estos diccionarios suelen ser bastantes explícitos a la hora de indicar la preposición exigida por el verbo; sin embargo, son bastante parcos por lo que se refiere a establecer los distintos tipos de argumentos exigidos por el verbo. Basándonos de nuevo en la clasificación establecida por Cano Aguilar, hay verbos pronominales como apresurarse (o dedicarse o atenerse, etc.) que exigen la presencia do la preposición a seguidos de sustantivo abstracto o infinitivo:

Se apresuró a llegar a la conferencia

Nos dedicamos a la creación de sistemas informáticos

Si te vas, atente a las consecuencias

Después de revisar los artículos de los verbos escogidos, todos ellos indican mediante diversos procedimientos (subrayado en cl ejemplo, notas gramaticales al final o junto a la acepción) que el verbo precisa de la preposición a. Pero ninguno aporta información sobre el tipo de complemento que rige el verbo desde el punto de vista sintáctico-semántico.

Este hecho no es algo puntual. Tomemos otro ejemplo. Los verbos pronominales como acordarse (o asegurarse o despreocuparse o arrepentirse) son verbos indicadores de actividades o proccsos mentales que exigen en esta construcción la preposición de:

No se ha acordado de las fotos / de comprar zanahorias para el estofado i de que tenía cita can el dentista

Si nos fijamos en el complemento, este sirve para indicar el 'contenido' de dicho proceso mental y se expresa a través de una oración o sustantivo abstracto ( $2^{\mathrm{a}}$ y $3^{\mathrm{a}}$ oración) o su referente $\left(1^{a}\right.$ oración). Todos los diccionarios revisados dejan explícito en sus artículos la exigencia de la preposición de regida por el complemento, pero ninguno aporta información sobre las características sintáctico-semánticas del complemento que rigen.

Tras esta sucinta muestra que homos ido analizando, podemos concluir que en los diccionarios dedicados a hablantes no nativos no es suficiente con indicar las distintas acepciones; estas tienen que ir acompañadas do las indicaciones necesarias acerca de las particularidades construccionales de cada una de ellas, pero además diferenciando los diferentes argumentos sintáctico-scmánticos exigidos por el verbo en cada una de esas construcciones, necesidad 
que, aunque no sicmpre se alcance, al menos sí se debería tener en cuenta en la elaboración de estos diccionarios.

Otra cuestión fundamental quc deben tener en cuenta los diccionarios monolingïes de aprendizaje es la indicación del 'contorno' en la definición, concepto descrito por Seco (1979) para diferenciar aquellos clementos que forman parte de la delinición de aquellos elementos que son imprescindibles para la construcción. Como dice Porto Dapena (1997: 21) es especialmente «en las definiciones de los verbos donde el contomo aparece con mayor frecuencia», ya que es necesario marcar aquellos elementos que son imprescindibles para construir un enunciado correcto, pero que no forman parte de su contenido léxico. En cl caso de los verbos son los argumentos verbales que se precisan para establecer la estructura sintáctica.

La mayoría de los diccionarios estudiados incluyen esta información de forma regular. A este respecto, se pueden hacer dos observaciones:

- Hay diccionarios que aportan esta información en todas las definiciones y así lo indican en la introducción.

DSLE (p. XI): «Verbos En todas las definiciones aparece marcado el tipo de sujeto con un paréntesis en ángulo $>$. Los complementos se marcan con los corchetes [ ]. El complemento directo de persona lleva la preposición $a$ dentro del corchete. Los otros complementos llevan las preposiciones fuera.

DES (p. X): «definición (en los verbos, con el tipo de sujeto — cntre barras verticales partidas-y de complementos- entrc paréntesis, en los casos en los que proceda»

- Otros diccionarios justifican en los preliminares la ausencia de esta información.

DIPELE (p. XVT): «A propósito de la definición de los verbos, en le inicio del proceso de redacción se pretendió llevar a la práctica una de las técnicas de definición que caracterizan a los diccionarios VOX: la de incluir entre paréntesis o corchetes el objeto directo y el indirecto para hacer posible la sustitución en los ejemplos de la definición por el definido. Sin cmbargo, se decidió no aplicar este criterio por razones diversas, aunque ello haya supuesto, y lo sentimos, caer en cierta heterodoxia lexicográfica. Una de las razones que nos llevaron a tomar esta decisión estuvo en el deseo de no recargar el artículo con signos y datos que hicieran difícil la comprensión o que pusieran en peligro la inmediatez de la consulta. Téngase en cuenta que, además del lcma, sc incluye una transcripción, información gramatical, ejemplos, obscrvaciones diversas, etc., y que el lector no siempre es un avezado usuario de diccionarioss. . $^{19}$

DFF. (p. 10): «En el caso de los verbos, la fórmula [de la definición] permite extraer el sujeto, el complemento directo o el complemento preposicional regidom.

En ocasiones, se intenta suplir esa ausencia de información sintáctica con ejemplos que reffejen el uso del verbo en cada una de las acepcioncs. Muchas veces estos diccionarios no indican la cxistencia de un complemento preposicional obligatorio ni la preposición exigida

19 Aunque no figure esta información en la definición, cl DIPELE incluye de manera sistemática en los verbos una indicación entre paréntesis que nos muestra el tipo de complemento (algo, alguicn) cxigido en la construcción sintáctica de ese verbo. 
por el verbo, pero estas características se obscrvan en los ejemplos ${ }^{20}$ que acompañan a la acepción. Ej.:

DSLE constar $v$. inir. 2. Estar <una persona o una cosa> registrada en [un lugar]: St teléfono no consta en la ficha. 3. Estar <una cosa> formada por [otras cosas]: El curso consta de dos cuatrimestres

Sin embargo, los ejemplos escogidos por el diccionario no sicmpre recogen de forma adecuada las características sintácticas del verbo descrito.

DSLE enojar $t r$. causar <una persona o cosa> enfado a [una persona] La entrenadora se enoja si el equipo no funciona / prnl. Mostrar <una persona> enfado por una cosa: Te enojaste innecesariamente con los amigos. Se enoja por cualquier cosa.

\section{Conclusiones}

A partir del análisis descriptivo que se ha realizado sobre la prescncia del verbo en los diccionarios didácticos monolingües del español, podemos decir que estos diccionarios dan una importancia considerable a la presencia de información verbal, lo cual, sin duda, sc debe a que son obras destinadas al aprendizaje de la lengua materna o de una lengua extranjera y por tanto deben hacer hincapié en uno de los pilares o núcleos de las estructuras gramaticales: el verbo; de ahí que todos los diccionarios incluyan los modelos de conjugación del español, ya que facilita al alumno el acceso a esta información de forma rápida.

Pero el lugar donde se sitúa esa información sobre la flexión verbal es variable. La tendencia observada es que los diccionarios monolingües de aprendizaje sitúen esta información en apéndices finales, o bien ordenados alfabćticamente o bien mediante una clasificación a partir de los distintos tipos de verbo que hay en español o a partir de la diferenciación entre alteraciones fónicas o gráficas e irregularidades propiamente dichas que presentan los verbos.

Con respecto a la forma hay uniformidad a la hora de incluir el infinitivo como representante canónico del paradigma verbal. No obstante, también encontramos otras variantes verbales como entradas, tales como el participio. En este caso hay menos sistematización a la hora de introducirlos, pero se observa que se valoran más los cambios semánticos o cambios de calegoría gramatical que lo que son variaciones morfológicas; de ahí que no se incluyan participios regulares sin modificación semántica y raramente participios irregulares con sólo valor verbal. Además, dado el carácter didáctico de estas obras, quc deben servir no solamente para la descodificación o comprensión, sino también para la codificación y producción de enunciados correctos y gramaticales en la lengua que se está aprendiendo, consideramos necesaria la presencia de las formas léxicas irregulares de un verbo en la nomenclatura del diccionario y su remisión a la forma verbal que representa ese paradigma, especialmente en el caso de los diccionarios monolingües de aprendizaje.

20 Dejamos para un futuro trabajo el estudio de los ejemplos que aportan estos diccionarios, donde además de establecer una tipología sobre el ejemplo, qucremos comprobar si la inlormación contenida en ellos refleja las particularidades descritas en la definición y sirve para aclarar dudas sobre el entorno sintáctico o de otro tipo. 
El análisis realizado a los diccionatios que hemos tomado como objeto de esludio muestra una creciente preocupación por incluir información de carácter gramatical que pueda resultar útil a los destinatarios de estas obras desde el punto de vista productivo y no sólo receptivo de enunciados. Tras la mucstra analizada podemos concluir que en los diccionarios dedicados a hablantes no nativos no es suficiente con indicar las distintas acepciones de significado; estas tienen que ir acompañadas de las indicaciones necesarias acerca de las particularidades construccionales de cada una de ellas, pero además diferenciando los diferentes argumentos sintáctico-semánticos exigidos por el verbo en cada una de esas construcciones. Aunque se mantiene la marcación tradicional de la categoría y subcategoría gramatical, se observa ya un avancc en relación con algunos aspectos:

- Una mayor sistematización a la hora de incorporar la información sobre el régimen preposicional en el verbo.

- Una mayor sistematización al separar los elementos del contorno de la definición de los elementos que explican el significado.

- Una presencia considerable de ejemplos, prácticamente en todas las acepciones.

Sin embargo, son bastante menos sistemáticos a la hora de incorporar la información sobre el entorno sintáctico. Queremos dejar claro que una obra lexicográfica no puede incorporar todos los usos gramaticales de cada una de las entradas, ya que entonces el diccionario se convertiría en una obra que recoge la gramática particular de cada palabra, lo cual no es el objetivo del diccionario. No cabe duda de que este tipo đe información debe incorporarse, pero es difícil establecer los límites acerca de de cuánta gramática debe aparecer en los diccionarios.

Como decíamos al principio de este artículo es el tipo de diccionario el que debe establecer los límites. Fn el caso que nos ocupa, los diccionarios dirigidos a hablantes no nativos con un dominio idiomático considerable, deben incorporar toda aquella información que describa el funcionamiento sintáctico y semántico de cada palabra si queremos que el diccionario sca algo más que un instrumento descodificador.

\section{REFERENCIAS BIBLIOGRÁFICAS}

AHum ADA IARA, I. (1988): «INFORM ACIÓN GRAM AIICAL IM PUiCITA EN LA DEfINICIÓN IEXICOGRÁficA», Thesaurus XLIII, págs. 81-94.

Ahumada Lara, 1. (2003): «Exigencias al diccionario monolingüe de aprendizaje». En S. Rushtaller, págs. 83-96

Aitchison, J. (1994): Words in The Mind. An introduction to the mental lexicon. Oxford, Blackwell. Alvar Ezquerra, M. (1993): Lexicografia descriptiva, Barcelona, Biblograf.

Alvar Ezquerra, M. (2003): Madrid: Arco libros.

Ayala Castro, M. C. (coord.) (2001): Diccionario y enseñanza. Alcalá de Henares, Publicaciones de la Universidad.

Azorín Fernándcz, D. (1994): «El diccionario como instrumento didácticon. En Comunicación y lenguaje, Universidad Internacional Mcnéndez Pelayo, Valencia, págs. 174-199.

Azorín Femández, D. \& Martínez Linares, M.A. (1994-95): «Léxico y sintaxis en los diccionarios monolingües del español». En Estudios de lingüística, 10, Departamento de Filologia Española, Lingüística General y Teoría de la Literatura, Universidad de Alicante, págs. 227-246. 
Azorín Fernández, D. \& Martínez Linares, M.A. (1996): «La definición lexicográfica: revisiones y propuestas». En J. A. Molina Redondo y Juan de Dios Luque Durán, Estudios de Lingüística General (III), Granada, Seric Collectac.

Azorín Fernández, D. (2000): «Zara qué usan el diccionario los escolares? Reflexiones a propósito de una encuesta). Lin S. Ruhstaller \& J. Prado Aragonés, Tendencias en la investigación lexicográfica del español, Universidad de Huelva, Publicaciones, págs. 75-100.

Azorín Fernández, D. \& Martínez Linares, M.A. (2000): «El tratamiento lexicográfico de los usos pronominales de los verbos transitivos en los diccionarios monolingües del cspañol actual». En M. Martínez Hernández et al. (eds.), Actas del Congreso de Semántica: Cien años de Semóntica. De M. Bréal a la actualidad, Madrid: Ediciones Clásicas, págs. 235-349.

Azorín Fernández, D. \& Martínez Linares, M.A. (200): «Léxico y gramática: repercusiones de un debate teórico en la historia reciente de los diccionarios del cspaniol». En

Azorín Fernández, D. \& J. Climent de Benito (2003). «El diccionario como instrumento didáctico en la enseñanza/aprendizaje de E/LE. Resultados de una encuesta», Actas de Asociación española de Lingüistica Aplicada (AESLA), mayo de 2003, Universidad de Lugo (en prensa).

Baralo, M. (1997): «La organización del lexicón en lengua extranjera». En Revista de Filología Románica. Homenaje a Pedro Peira Soberón, 14, vol, 1, págs. 59-73

Bargalló, M. (1999): «La información gramatical en los diccionarios didácticos del español». En Neus Vila, M. et al. (eds.), Asi son los diccionarios, Lleida: Universitat de Lleida, págs. 15-42.

Calderón Campos, R. (1994): Sobre la elaboración de diccionarios monolingües de producción: las definiciones, los ejemplos y las colocaciones léxicas. Granada, Publicacines de la Universidad.

Calero Heras, José (1992): Entre palabras. Para aprender a manejar el diccionario, Barcelona, Octoedro.

Cano Aguilar, R. (1999): «Los complementos de régimen verbal». En Bosque, I. y V. Demonte (dirs.): Gramática descriptiva del español. Madrid, Espasa, págs. 1807-1854.

Consejo de Europa, (2002), Marco de referencia europen para el aprendizaje, la enseñanza y la evaluación de lenguas (traducción a cargo de Instituto Cervantes), MECD, Anaya: http://cve. cervantes.es/obrel/marco/cap 01.htm

Corpas Pastor, G.; Leiva Rojo, J.; Valera Salinas, M. J. (2001), «El papel del diccionario en la formación de traductores e intérpretes: análisis de necesidades y encuestas de usom. En M. C. Ayala Castro (coord.), Diccionario y enseñanza, Alcalá, Servicio de Publicaciones de la Universidad, págs. 239-273.

Gelpi Arroyo, C. (1997), Mesures d'avahuació lexicogràfica dels diccionaris bilingïes, [Tesis Doctoral inédita], Barcelona, Universitat Pompeu Fabra.

Haensch, G.; Wolf, L.; Ettinger, S.; werner, R. (1992): La lexicografia. De la lingǘstica teórica a la lexicografia práctica, Madrid, Gredos.

Haensch, G. (1999): Los diccionarios del español en el umbral del siglo XXI, Salamanca, Publicaciones de la Universidad

Hernández, H. (1993): «De la teoría lexicográfica al uso del diccionario: el diccionario en el aula». En Actas del $3^{\circ}$ Congreso Nacional de ASELEX, Málaga, págs. 189-199.

Hernández, H. (1993): «El despegue de la lexicografía escolar (a propósito de Intermedio). En Alacena, $\mathrm{n}^{\circ} 17$, págs. $34-35$.

Hernández, H. (1996): «La lexicografia didáctica: los diccionarios escolares del español en el último cuarto de siglo». En Cuadernos Cervantes, 11, noviembre-diciembre, págs. 24-36.

Maldonado González, C. (1998): El uso del diccionario en el aula. Madrid: Arco libros.

Marimón, C. \& J. A. Candalija (2000): «El diccionario como objcto de cstudio linguístico y didáctico». En S. Ruhstaller \& J. Prado Aragonés, Tendencias en la investigación lexicográfica del español, Universidad de Huelva, Publicaciones, págs. 311-321.

Moreno Fernández, F. (1996): «El diccionario y la enseñanza del español como lengua cxtranjera». En Cuadernos Cervantes, 11, noviembre-diciembre, págs. 47-58. 
Rojo, G. (1997): «Gramática y diccionario». En González, J. M. y J. Terrón (eds.), Actas II Jornadas de metodología y didáctica de la lengua española, Extremadura, Universidarl, págs. 33-48.

Rundell, M. (1998): «Recent trenes in english pedagogical lexicography». En International Journal of Lexicography, vol. 11 Number 4, págs. 315-342.

Santamaría Pérez, M. I. (2000): «La frascología en los diccionarios didácticos del español». En S. Ruhstaller \& J. Prado Aragonés, Tendencias en la investigación lexicográfica del español, Universidad de Huelva: Publicaciones, págs. 559-571.

Santamaría Pérez, M. I. (2003): «¿Para qué usan el diccionario los traductores?: Reflexiones a partir de una encuesta\%. En Actas del III Congreso de la Asociación española de Lingüistica Aplicada, mayo de 2003, Universidad de Lugo (en prensa)

Santamaría Pérez, M. I. (2003): La fraseología española en los diccionarios bilingües español-catalán: aplicaciones y contrastes, Universidad de Alicante, Publicaciones.

Schafroth, E. (1998): «Consideraçoes sobre um diccionario de aprendizagemde língua portuguesa». En M. T. Fuentes Morán y R. Werner, Lexicografias iberorrománicas: problemas, propuestas y proyectos. Frankfurt am Main, Vervucrt Verlag, págs. 97-119.

Veiga, Alexandre; Víctor M. Longd y Jodee Anderson (eds.) (2001): El verbo entre el léxico y la gramática, Lugo: Editorial Tris Tram. 